\title{
ZINC RESISTANCE OF SIX DARK SEPTATE ENDOPHYTIC FUNGI AND THE GROWTH RESPONSE OF TOMATO
}

\author{
LIN, L. C. \\ Department of Forestry and Natural Resources, National Chiayi University \\ Chiayi, Taiwan 60004, Republic of China \\ (e-mail: linerm@mail.ncyu.edu.tw; phone: +886-5-271-7474; fax: + 86-5-271-7467) \\ (Received $3^{\text {rd }}$ Sep 2019; accepted $15^{\text {th }}$ Nov 2019)
}

\begin{abstract}
Dark septate endophytic fungi (DSEF) can promote the growth response of host plants and can increase their resistance to heavy metals. In this study, six isolated DSEFs were proven to be able to form microsclerotia with plants. The objective of this study was to investigate the promoting and inoculation effects of these six DSEFs. Molecular analysis showed that the DSEFs may be new additions to the fungal flora of Taiwan and may be new species in the world. Screening and selection of Zn-resistant DSEFs showed that only two strains, CkDB5 and RrtHH10, were Zn-resistant. Evaluation of the Zn resistance range of CkDB5 and RrtHH10 revealed that the former presented lower $\mathrm{EM}_{50}$ values than the latter, and that both strains showed the same minimum inhibitory concentration values. As the $\mathrm{Zn}$ concentration increased, twisting and looping of the mycelial morphology of the strains was observed. Resynthesis experiments proved that CkDB5 and RrtHH10 could promote the growth response of tomato. The biomasses of CkDB5-inoculated plants was up to four times higher than that of the controls. This study showed that, of the six DSEFs, only CkDB5 and RrtHH10 showed Zn-resistance. CkDB5 is a fungus with particularly high $\mathrm{Zn}$ resistance, and it could facilitate tomato growth.
\end{abstract}

Keywords: dark septate endophytic fungi, growth response, half maximal effective, resynthesis, Zn-resistant

\section{Introduction}

Heavy metals are some of the most toxic inorganic substances known to mankind, and they can contaminate the environment (Upadhyaya et al., 2010). Phytoremediation removes heavy metals through synthesis with plants and microorganisms; to date, it remains the best strategy for heavy-metal recovery with the least harmful effects to the environment (Diagne et al., 2015; Helmisaari et al., 2007). Mycorrhizae promote the growth (Azcón-Aguilar and Barea, 1997; Schmid et al., 1995) and tolerance (Gibson and Mitchell, 2005; Lin et al., 2011) of host plants. Mycorrhizal associations have also been shown to enhance the tolerance of host plants to $\mathrm{Zn}$ and $\mathrm{Cu}$ (Bradley et al., 1981). Some fungi can alleviate toxic metal stress under certain circumstances (Smith and Read, 1997).

Dark septate endophytic fungi (DSEFs), which are commonly found in the roots of healthy plants, present dark pigmentation and septate hyphae (Mathew and Malathy, 2008) and are often sterile in culture (Newsham, 1999; Piercey et al., 2004). DSEFs refer to miscellaneous groups of anamorphic ascomycetous fungi that can colonize the intracellular or intercellular tissues of roots, and maintain an important functional relationship with host plants. DSEFs can enhance the growth and mineral nutrition of hosts (Fernando and Currah, 1996; Jumpponen et al., 1998; Lin, 2016; Shivanna et al., 1994). Several studies have indicated that some endophytes could promote the growth of host plants in soils that have been contaminated by heavy metals (Monnet et al., 2001; Sun et al., 2011; Xu et al., 2015; Zhang et al., 2010).

$\mathrm{Li}$ et al. (2012) suggested that fungal endophyte colonization in $\mathrm{Pb}-\mathrm{Zn}$ contaminated plants is moderately abundant and that some isolates adapt remarkably well to $\mathrm{Pb}^{2+}$ and 
$\mathrm{Zn}^{2+}$. These findings indicate a potential application in phytoremediation. Diao et al. (2013) indicated that $\mathrm{Zn}$ is an essential micronutrient required by a wide variety of cellular processes. However, excessive $\mathrm{Zn}$ can be toxic to organisms (Jaeckel et al., 2005). Zn is also proposed in the 13-metal contamination list published by the US Environmental Protection Agency (Ramos et al., 2002). In the laboratory, many researchers have demonstrated that DSEF isolates could facilitate the growth of host plants. However, the $\mathrm{Zn}$ resistance of these DSEFs to various metal concentrations remains unknown. The purpose of this study is to examine the response of six DSEFs to Zn.

\section{Material and methods}

\section{Strains}

Six DSEFs were used in this study. Strains CkDB2 and CkDB5 were previously isolated from the roots of Cinnamomum kanehirae (12047'37.33" E, 23²8'16.12" N) from a plantation located in Dabang Township, Chiayi County, Taiwan (Hong et al., 2014). Strain CoLG3 was previously isolated from the roots of $C$. osmophloeum $\left(120^{\circ} 47^{\prime} 15^{\prime \prime} \mathrm{E}, 23^{\circ} 43^{\prime} 47^{\prime \prime} \mathrm{N}\right)$ in a plantation located in Lugu Township, Nantou County, Taiwan. Strain MoAL5 was previously isolated from the roots of Mahonia oiwakensis $\left(120^{\circ} 48^{\prime} 45^{\prime \prime} \mathrm{E}, 23^{\circ} 30^{\prime} 46^{\prime \prime} \mathrm{N}\right)$ in a plantation located in Alishan Township, Chiayi County, Taiwan (Tan et al., 2016). Strain RhYM6 was previously isolated from the roots

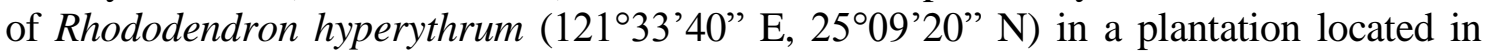
Beitou District, Taipei City, Taiwan. Finally, strain RrtHH10 was previously isolated from the roots of $R$. rubropilosum var. taiwanalpinum $\left(121^{\circ} 17^{\prime} 21^{\prime \prime} \mathrm{E}, 2^{\circ} 09^{\prime} 58^{\prime \prime} \mathrm{N}\right.$ ) in a plantation located in Renai Township, Nantou County, Taiwan. These six strains were deposited at the Tree Mycorrhiza Laboratory of National Chiayi University.

\section{Seeds}

The seeds of ARIA tomatoes (Solanum lycopersicum L.) used in this experiment, were kindly provided by the Known-You Seed Co., Ltd.

\section{DNA extraction, sequencing and phylogenetic analysis}

The methods described by Phosri et al. (2007) were followed. Mycelia for deoxyribonucleic acid (DNA) extraction, amplification, and sequencing were scraped from the surfaces of PDA cultures. Genomic DNA was extracted using Puregene Proteinase K. Total fungal DNA was used as the template for amplification with primers ITS1-F and ITS4 (Gardes and Bruns, 1993). Polymerase chain reaction (PCR) products were sequenced by Genomics BioSci and Tech Company. Sequences were assembled and related sequences were analyzed using the basic local alignment search tool (BLAST) searches. The phylogenetic relationships were analyzed by Molecular Evolutionary Genetics Analysis software (Tamura et al., 2011). Bootstrapping was performed using neighbor-joining (Saitou and Nei, 1987).

\section{Screening and selection of Zn-resistant DSEFs}

Screening and selection of Zn-resistant DSEFs was performed using the methods of Ban et al. (2012) and Zeng et al. (2008) with modifications. The Zn-resistance of the six DSEFs was determined by placing two $0.5 \mathrm{~mm}^{3}$ plugs of the mycelium from each DSEF 
into an Erlenmeyer flask (125 mL) containing $25 \mathrm{~mL}$ of modified Melin-Norkrans liquid medium (MMN) (Marx, 1969). Each DSEF was placed in 6 flasks, 3 with Zn $\left(\mathrm{ZnCl}_{2}, 1 \mathrm{mg} / \mathrm{mL}\right)$ and another 3 without. After 14 days of cultivation, the flasks were autoclaved (liquid cycle at $121{ }^{\circ} \mathrm{C}$ for $20 \mathrm{~min}$ ), harvested by filtration (filter paper, AdvanTec No. 1), dried to a constant mass at $70^{\circ} \mathrm{C}$, and weighed.

\section{Evaluation of metal tolerance range}

Strains that survived cultivation in $\mathrm{Zn}$ medium were evaluated for their $\mathrm{Zn}$ tolerance range using the method of Ban et al. (2012) with modifications. The sensitivity of select DSEFs to $\mathrm{Zn}$ was evaluated by measuring their minimum inhibitory concentration (MIC) and the effective concentration inhibiting $50 \%$ of mycelial growth (EC50). Petri dishes with MMN medium (Marx, 1969) were used to cultivate the selected DSEFs for 14 days. Each DSEF was exposed to six Zn concentrations $(0,0.4,0.8,1.2,1.6$, and $2.0 \mathrm{mg} / \mathrm{mL})$ in three replicates. Two $0.5-\mathrm{cm}$ diameter plugs were removed from the edge of 14-day-old colonies and placed in flasks. All treated samples were harvested after incubation in the dark for 14 days, after which the flasks with medium were autoclaved (liquid cycle at $121{ }^{\circ} \mathrm{C}$ for 20 min), filtered (filter paper, AdvanTec No. 1), dried to a constant mass at $70{ }^{\circ} \mathrm{C}$, and weighed.

\section{Observation of mycelial morphology under different concentrations of $\mathrm{Zn}$}

All mycelium treatments were observed. After 14 days of cultivation in different concentrations of $\mathrm{Zn}$, several mycelia were obtained and carefully placed onto slides. Lactophenol cotton blue (BD BBL ${ }^{\mathrm{TM}}$ ) was applied to stain hyphae, and morphological observations were made using a light microscope; photos were taken for recording purposes (Hutton et al., 1994; Piercey et al., 2002; Sigler and Flis, 1998).

\section{Evaluation of the growth responses of tomato inoculated with DSEFs}

After the desired DSEFs were screened, they were applied to the roots of ARIA tomatoes under different environments with or without $\mathrm{Zn}$. Pure resynthesis was done through the method proposed by Dalpé (1986). After surface cleaning, tomato seeds were sterilized with $10 \%$ sodium hypochlorite solution for $15 \mathrm{~min}$, rinsed 3 times with sterilized distilled water, and then incubated in glass jars containing 1\% agar for germination. Germinated seedlings were transplanted to $100 \mathrm{~g}$ of peat substrate (containing $100 \mathrm{~mL}$ MMN medium with or without $\mathrm{Zn}\left(\mathrm{ZnCl}_{2}, 1\right.$ or $\left.0 \mathrm{mg} / \mathrm{mL}\right)$ ) in a glass jar $\left(95 \times 73 \mathrm{~mm}^{2}\right)$. Five aseptic tomato seedlings were inoculated with each DESF. Growth was then allowed to proceed for 42 days in a growth chamber $\left(22{ }^{\circ} \mathrm{C}, 65 \% \mathrm{RH}\right.$, and $16 \mathrm{~h}$ of light with a maximum illumination of 5,000 lx). To determine the growth responses of the plants, the seedlings were carefully removed from the jar after incubation.

\section{Evaluation of $Z$ n concentrations in tomato}

Evaluation of $\mathrm{Zn}$ concentrations in the seedlings was performed following the method described by Yang et al. (2015). Each plant sample was washed thoroughly with tap water and rinsed five times with deionized water to remove surface dust and soil. The cleaned samples were then dried at $80{ }^{\circ} \mathrm{C}$ in an oven for $48 \mathrm{~h}$ until a constant 
weight was achieved. Afterward, the samples were crushed using a microphyte disintegrator.

The concentrations of $\mathrm{Zn}$ in the plant samples were determined using the method described by Allen (1989). Samples were completely digested in concentrated $\mathrm{HNO}_{3}$ $(16 \mathrm{moL} / \mathrm{L})$ and $\mathrm{HClO}_{4}(12 \mathrm{moL} / \mathrm{L})$ at a ratio of $4: 1(\mathrm{v} / \mathrm{v})$. The digestion tubes were removed from the digestion block to cool. After the solution had cleared, it was filtered through AdvanTec No. 1 filter paper and transferred quantitatively into a $10-\mathrm{mL}$ volumetric flask by addition of distilled water. Metal concentrations were determined by flame atomic absorption spectrometry (FAAS).

\section{Statistical analyses}

Statistical Package for the Social Sciences (version 12.0) (Illinois, USA) for Windows was used for statistical analysis. Means of 3 or 5 separate experiments \pm standard deviations $(\mathrm{n}=3$ or 5$)$ were calculated from the collected data. Tukey's multiple range test at the $\mathrm{p} \leq 0.05$ significance level was used to analyze differences between treatments.

\section{Results}

\section{Molecular identification of six DSEFs}

The data matrix used to construct the neighbor-joining tree was comprised of 18 taxa and 704 aligned characters (including gaps/missing data) (Fig. 1). Based on the results of the phylogenetic analysis, the internal transcribed spacer (ITS) sequences of RrtHH10 clustered with those of Phialocephala, forming a cluster with $100 \%$ bootstrap support. RrtHH10 shared the closest sequence identity with Phialocephala fortinii (GQ302683). The ITS sequences of CoLG3 were similar to those of CkDB2 and clustered with those of Wiesneriomyces laurinus (KR822217; KP057801), forming a cluster with $100 \%$ bootstrap support. The ITS sequences of RhYM6 were clustered with those of Herpotrichiellaceae sp. (KJ471529) and Eurotiomycetes sp. (KM520020), forming a cluster with 98\% bootstrap support. The ITS sequences of MoAL5 were clustered with those of Cladophialophora, forming a cluster with $95 \%$ bootstrap support. MoAL5 shared the closest sequence identity with Cladophialophora chaetospira (EU035406). The ITS sequences of CkDB5 were clustered with those of Scolecobasidium, forming a cluster with $99 \%$ bootstrap support. CkDB5 shared the closest sequence identity with Scolecobasidium humicola (AY265334).

\section{Screening of Zn-resistant DSEFs}

After 14 days of incubation, the samples were harvested and dried at $70{ }^{\circ} \mathrm{C}$ until a constant weight was achieved (Table 1). In treatments without $\mathrm{Zn}$, all six DSEFs survived; in contrast, only strains CkDB5 and RrtHH10 survived in treatments with Zn.

In treatments without $\mathrm{Zn}$ (Table 1), strain CkDB2 showed the highest dry weight of $74.0 \pm 6.4 \mathrm{mg}$. By comparison, the dry weights of MoAL5, RrtHH10, RhYM6, CoLG3, and CkDB5 were $65.4 \pm 5.7,59.8 \pm 6.3,57.7 \pm 4.9,44.7 \pm 1.9$, and $39.2 \pm 3.2 \mathrm{mg}$, respectively.

In treatments with Zn (Table 1), only strains CkDB5 and RrtHH10 survived; the dry weights of these strains were $28.8 \pm 2.8$ and $29.5 \pm 1.2 \mathrm{mg}$, respectively. 


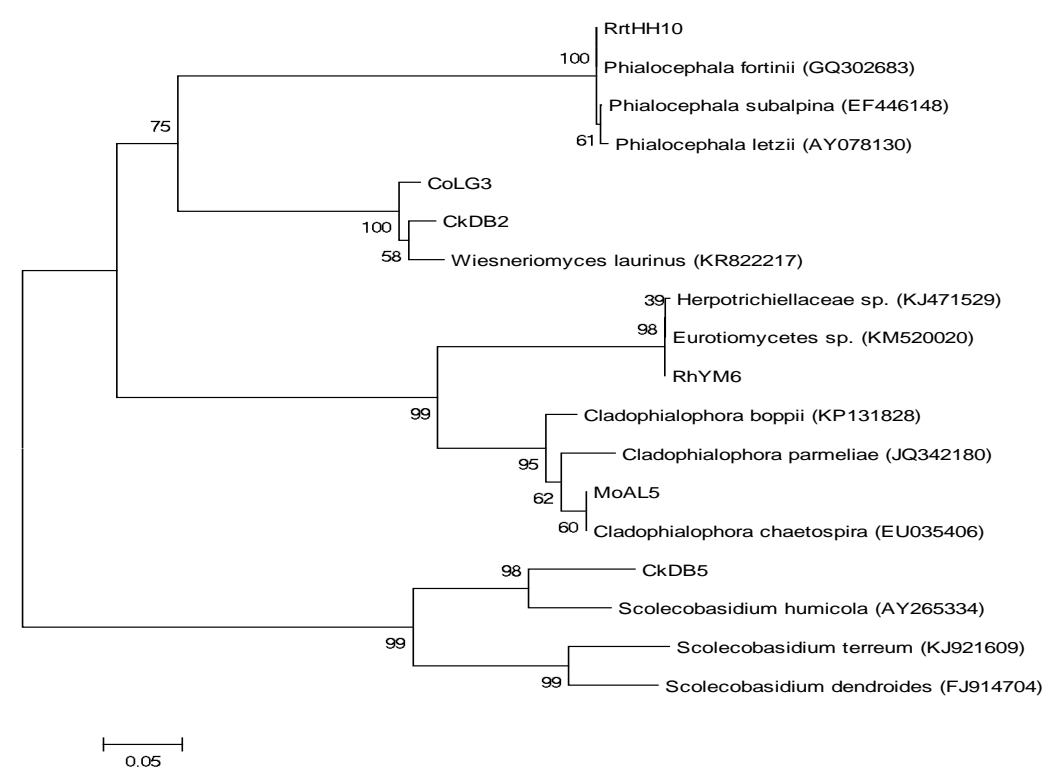

Figure 1. The neighbor-joining phylogenetic tree of the six strains of interest. The tree was obtained using the maximum composite likelihood model for pairwise distance measurements based on ITS sequences. Numbers on branches indicate values generated from 1,000 bootstrap replica

Table 1. Dry weights of six DSEFs in MMN medium with and without Zn

\begin{tabular}{c|c|c}
\hline \multirow{2}{*}{ Treatment (strain) } & \multicolumn{2}{|c}{ Dry weight (mg) } \\
\cline { 2 - 3 } & Zn-free & Zn \\
\hline CoLG3 & $44.7 \pm 1.9^{\mathrm{b}}$ & - \\
CkDB2 & $74.0 \pm 6.4^{\mathrm{a}}$ & - \\
CkDB5 & $39.2 \pm 3.2^{\mathrm{b}}$ & $28.8 \pm 2.8^{\mathrm{a}}$ \\
MoAL5 & $65.4 \pm 5.7^{\mathrm{b}}$ & - \\
RhYM6 & $57.7 \pm 4.9^{\mathrm{ab}}$ & - \\
RrtHH10 & $59.8 \pm 6.3^{\mathrm{ab}}$ & $29.5 \pm 1.2^{\mathrm{a}}$ \\
\hline
\end{tabular}

All values represent the means \pm standard deviations of three replicate cultures. Values in the same column with different letters indicate a difference at the $5 \%$ significance level

\section{Evaluation of Zn tolerance range}

Strains CkDB5 and RrtHH10 produced varying dry weights in media with different $\mathrm{Zn}$ concentrations after 14 days of incubation (Table 2).

Strain CkDB5 showed significantly different dry weights under different $\mathrm{Zn}$ concentrations (Table 2). The highest dry weight value in $0 \mathrm{mg} / \mathrm{mL}$ is $28.4 \pm 1.8 \mathrm{mg}$, compared to $0.4 \mathrm{mg} / \mathrm{mL}(22.1 \pm 4.2 \mathrm{mg}), 0.8 \mathrm{mg} / \mathrm{mL}(19.1 \pm 3.9 \mathrm{mg}), 1.2 \mathrm{mg} / \mathrm{mL}$ $(16.9 \pm 1.9 \mathrm{mg}), 1.6 \mathrm{mg} / \mathrm{mL}(16.0 \pm 2.5 \mathrm{mg}), 2.0 \mathrm{mg} / \mathrm{mL}(4.9 \pm 0.6 \mathrm{mg})$ and $2.4 \mathrm{mg} / \mathrm{mL}$ (0 mg).

Strain RrtHH10 also showed significantly different dry weights under different $\mathrm{Zn}$ concentrations (Table 2). The highest dry weight value in $0 \mathrm{mg} / \mathrm{mL}$ is $53.4 \pm 8.1 \mathrm{mg}$, compared to $0.4 \mathrm{mg} / \mathrm{mL}(42.4 \pm 16.0 \mathrm{mg}), 0.8 \mathrm{mg} / \mathrm{mL}(34.9 \pm 6.2 \mathrm{mg}), 1.2 \mathrm{mg} / \mathrm{mL}$ $(11.5 \pm 1.7 \mathrm{mg}), 1.6 \mathrm{mg} / \mathrm{mL}(7.7 \pm 1.9 \mathrm{mg}), 2.0 \mathrm{mg} / \mathrm{mL}(5.9 \pm 2.3 \mathrm{mg})$ and $2.4 \mathrm{mg} / \mathrm{mL}$ (0 mg). 
Table 2. Dry weights of strains CkDB5 and RrtHH10 in MMN medium with different Zn concentrations

\begin{tabular}{c|c|c}
\hline \multirow{2}{*}{$\begin{array}{c}\text { Zn concentrations } \\
(\mathbf{m g} / \mathbf{m L})\end{array}$} & \multicolumn{2}{|c}{ Dry weight (mg) } \\
\cline { 2 - 3 } 0 & $28.4 \pm 1.8^{\mathrm{a}}$ & RrtHH10 \\
0.4 & $22.1 \pm 4.2^{\mathrm{ab}}$ & $53.4 \pm 8.1^{\mathrm{a}}$ \\
0.8 & $19.1 \pm 3.9^{\mathrm{b}}$ & $42.4 \pm 16.0^{\mathrm{a}}$ \\
1.2 & $16.9 \pm 1.9^{\mathrm{b}}$ & $34.9 \pm 6.2^{\mathrm{a}}$ \\
1.6 & $16.0 \pm 2.5^{\mathrm{b}}$ & $11.5 \pm 1.7^{\mathrm{b}}$ \\
2.0 & $4.9 \pm 0.6^{\mathrm{c}}$ & $7.7 \pm 1.9^{\mathrm{b}}$ \\
2.4 & $0^{\mathrm{d}}$ & $5.9 \pm 2.3^{\mathrm{b}}$ \\
\hline
\end{tabular}

All values represent the means \pm standard deviations of three replicate cultures. Values in the same column with different letters indicate a difference at the $5 \%$ significance level

\section{Morphological changes of the DSEFs under different Zn concentrations}

The mycelial morphology of strains CkDB5 and RrtHH10 were observed under a light microscope after cultivation in $\mathrm{MMN}$ medium with different $\mathrm{Zn}$ concentrations for 14 days. Strains CkDB5 (Fig. 2A-C) and RrtHH10 (Fig. 2D-F) showed notable morphological changes in the presence of different $\mathrm{Zn}$ concentrations.
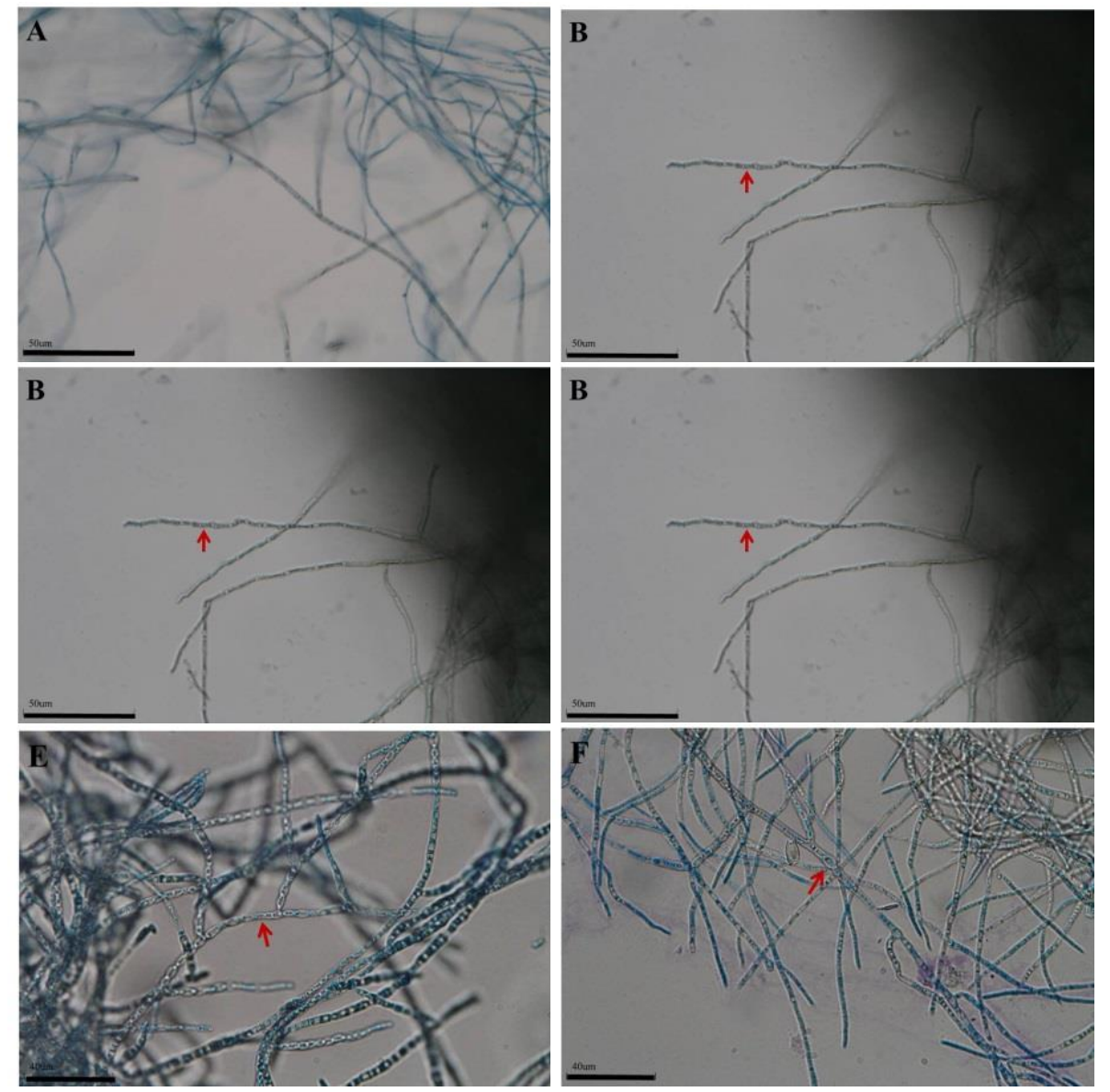

Figure 2. Mycelial morphology of strains CkDB5 and RrtHH10 in different Zn concentrations. A-C. Strain CkDB5. D-F. RrtHH10. A and D, $0 \mathrm{mg} / \mathrm{mL}$. B and E, $0.8 \mathrm{mg} / \mathrm{mL}$. C and F, 1.6 $m g / m L$ 


\section{Growth response}

After 42 days of incubation, all treated tomato seedlings (with/without $\mathrm{Zn}$ ) had survived (Fig. 3), and the fresh weights of all treatments showed significant differences $(\mathrm{p}<0.05)$ (Table 3).
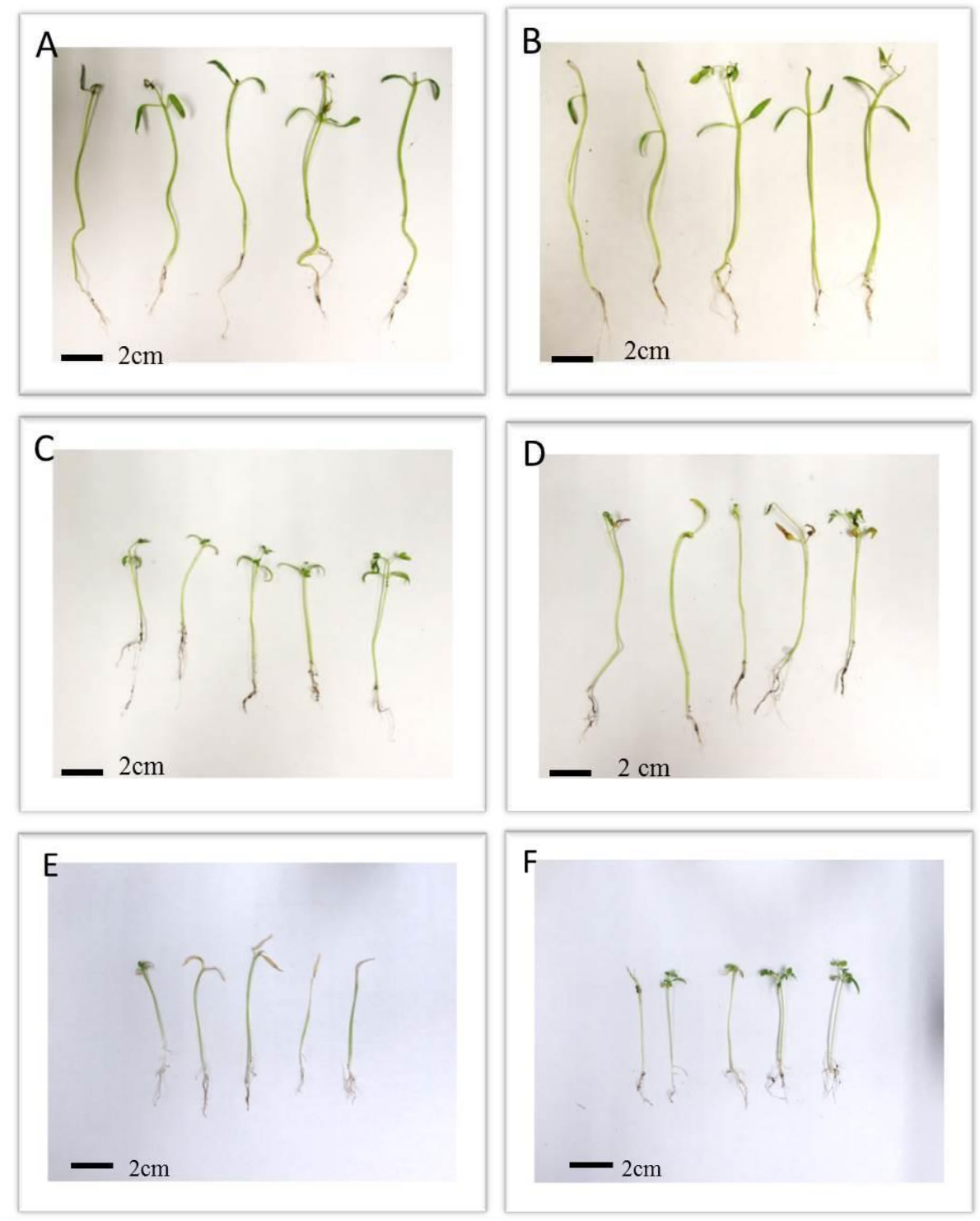

Figure 3. Morphology of tomato seedlings after incubation for 42 days. A. Plants inoculated with CkDB5 without Zn. B. Plants inoculated with CkDB5 with Zn. C. Plants inoculated with RrtHH1O without Zn. D. Plants inoculated with RrtHH1O with Zn. E. Controls without Zn. F. Controls with $\mathrm{Zn}$

In treatments without $\mathrm{Zn}$ (Table 3), plants inoculated with CkDB5 generated the highest fresh weights of $229.2 \pm 5.1 \mathrm{mg}$ compared to plants inoculated with RrtHH10 $(81.5 \pm 3.3 \mathrm{mg})$ and the control $(54.7 \pm 3.4 \mathrm{mg})$.

In treatments with $\mathrm{Zn}$ (Table 3), plants inoculated with CkDB5 also showed the highest fresh weights, $174.4 \pm 11.4 \mathrm{mg}$, compared to plants inoculated with RrtHH10 $(104.3 \pm 11.2 \mathrm{mg})$ and the control $(49.7 \pm 4.0 \mathrm{mg})$. 
Table 3. Biomasses of tomato seedlings grown for 42 days in different treatments

\begin{tabular}{c|c|c|c}
\hline \multirow{2}{*}{$\begin{array}{c}\text { Treatment } \\
\left(\mathbf{m g ~ m}_{\mathbf{~}}^{-\mathbf{1}}\right)\end{array}$} & \multicolumn{3}{|c}{ Fresh weight $(\mathbf{m g})$} \\
\cline { 2 - 4 } & CkDB5-inoculation & RrtHH10-inoculation & Control \\
\hline 0 & $229.2 \pm 5.1^{\mathrm{aA}}$ & $81.5 \pm 3.3^{\mathrm{bB}}$ & $54.7 \pm 3.4^{\mathrm{aC}}$ \\
1 & $174.4 \pm 11.4^{\mathrm{bA}}$ & $104.3 \pm 11.2^{\mathrm{aB}}$ & $49.7 \pm 4.0^{\mathrm{aC}}$ \\
\hline
\end{tabular}

All values represent the means \pm standard deviations of five replicate cultures. Values in the same row with different lowercase letters are significantly different at 5\% significant level. Values in the same column with different capital letters are significantly different at 5\% significant level

\section{Evaluation of Zn concentrations in tomato}

At harvest, the $\mathrm{Zn}$ concentrations of all treatments were determined by FAAS. The $\mathrm{Zn}$ concentrations of all treatments with $\mathrm{Zn}$ showed significant differences compared to all treatments without $\mathrm{Zn}(\mathrm{p}<0.05)$ (Table 4).

In treatments without $\mathrm{Zn}$ (Table 4), plants inoculated with CkDB5 showed the highest $\mathrm{Zn}$ concentration $(92.99 \pm 0.5 \mu \mathrm{g} / \mathrm{g})$ compared to the control $(56.4 \pm 4.5 \mu \mathrm{g} / \mathrm{g})$ and plants inoculated with RrtHH10 $(0 \mu \mathrm{g} / \mathrm{g})$.

In treatments with Zn (Table 4), plants inoculated with RrtHH10 demonstrated the highest $\mathrm{Zn}$ concentration $(1,083.03 \pm 13.0 \mu \mathrm{g} / \mathrm{g})$ compared to plants inoculated with CkDB5 $(912.83 \pm 6.2 \mu \mathrm{g} / \mathrm{g})$ and the control $(279.09 \pm 6.3 \mu \mathrm{g} / \mathrm{g})$.

Table 4. Zn concentrations of tomato seedlings grown for 42 days in different treatments

\begin{tabular}{c|c|c|c}
\hline \multirow{2}{*}{$\begin{array}{c}\text { Treatment } \\
\left(\mathbf{m g ~ m L}^{-\mathbf{1}}\right)\end{array}$} & \multicolumn{3}{|c}{ Zn concentration $(\boldsymbol{\mu g} / \mathbf{g})$} \\
\cline { 2 - 4 } & CkDB5-inoculation & RrtHH10-inoculation & Control \\
\hline 0 & $92.99 \pm 0.5^{\mathrm{bA}}$ & $0^{\mathrm{bC}}$ & $56.4 \pm 4.5^{\mathrm{bB}}$ \\
1 & $912.83 \pm 6.2^{\mathrm{aB}}$ & $1083.03 \pm 13.0^{\mathrm{aA}}$ & $279.09 \pm 6.3^{\mathrm{aC}}$ \\
\hline
\end{tabular}

All values represent the means \pm standard deviations of five replicate cultures. Values in the same row with different lowercase letters are significantly different at $5 \%$ significant level. Values in the same column with different capital letters are significantly different at 5\% significant level

\section{Discussion}

In our laboratory, six isolates were shown to be DSEFs, which are known to facilitate the growth of host plants. The six isolates belonged to five taxa (Fig. 1); CoLG3 and CkDB2 belonged to W. laurinus, RrtHH10 belonged to P. fortinii, CkDB5 belonged to $S$. humicola, RhYM6 belonged to Herpotrichiellaceae, and MoAL5 belonged to $C$. chaetospira.

All six DSEFs that were cultivated in treatments without $\mathrm{Zn}$ survived after incubation for 14 days, but only strains CkDB5 and RrtHH10 survived in treatments with Zn (Table 1). Although strains CkDB5 and RrtHH10 did not show significant growth in MMN medium without Zn, they unexpectedly survived in MMN medium with $\mathrm{Zn}$. Therefore, strains CkDB5 and RrtHH10 were selected for further study (Table 1).

The sensitivity of strains CkDB5 and RrtHH10 to Zn was determined based on MIC and $\mathrm{EC}_{50}$. Following the different $\mathrm{Zn}$ concentrations in MMN medium for evaluation of $\mathrm{Zn}$ tolerance range (Table 2), strain CkDB5 had shown significant differences at a lower Zn concentration $(0.8 \mathrm{mg} / \mathrm{mL})$, while strain RrtHH10 showed significant differences at a higher $\mathrm{Zn}$ concentration $(1.2 \mathrm{mg} / \mathrm{mL})$. The MIC of CkDB5 was over $2.0 \mathrm{mg} / \mathrm{mL}$, and its $\mathrm{ME}_{50}$ was over $1.6 \mathrm{mg} / \mathrm{ml}$. The MIC of RrtHH10 was over $2.0 \mathrm{mg} / \mathrm{mL}$, and its $\mathrm{ME}_{50}$ 
was over $0.8 \mathrm{mg} / \mathrm{mL}$. Strain CkDB5 showed the same $\mathrm{Zn}$ resistance as the fungal endophyte H93 (EU797525) $\left(\mathrm{ME}_{50}=1.5 \mathrm{mg} / \mathrm{mL}\right)$ (Zhang et al., 2008). Therefore, strain CkDB5 could belong to a group of highly tolerant fungi based on the studies by Wainwright and Gadd (1997) and Zhang et al. (2008). The mycelial morphology of the strains was twisted and looped with increasing $\mathrm{Zn}$ concentrations (Fig. 2). Ban et al. (2012) and Zhang et al. (2008) reported similar results.

Although all treated tomato seedlings (with/without $\mathrm{Zn}$ ) survived 42 days of incubation (Fig. 3; Table 3), the fresh weights of plants inoculated with CkDB5 and RrtHH10 were significantly higher than those of the control. The fresh weight of plants inoculated with CkDB5 without $\mathrm{Zn}(229.2 \pm 5.1 \mathrm{mg})$ was significantly higher than that of plants inoculated with CkDB5 with $\mathrm{Zn}(174.4 \pm 11.4 \mathrm{mg})$. Compared to the fresh weight of the control $(54.7 \pm 3.4 \mathrm{mg})$, the fresh weight of plants inoculated with CkDB5 without $\mathrm{Zn}$ was 4 times higher $(229.2 \pm 5.1 \mathrm{mg})$. Compared to the fresh weight of the control $(54.7 \pm 3.4 \mathrm{mg})$, the fresh weight of plants inoculated with RrtHH10 without $\mathrm{Zn}$ was only 1.6 times higher $(81.5 \pm 3.3 \mathrm{mg})$. DSEFs can enhance the growth of their host plant (Fernando and Currah, 1996; Jumpponen et al., 1998; Shivanna et al., 1994). While strain CkDB5 could increase the biomass of C. kanehirae cuttings by $200 \%$ (Lin, 2016), the same strain increased the biomass of inoculated tomatoes by up to $400 \%$ in this study (Table 3).

Of the six treatments (Table 4) studied, the $\mathrm{Zn}$ concentration of plants inoculated with RrtHH10 with $\mathrm{Zn}$ was 1,000 times higher than that of plants without $\mathrm{Zn}$. The $\mathrm{Zn}$ concentration of plants inoculated with CkDB5 with $\mathrm{Zn}$ was 10 times higher than that of plants without $\mathrm{Zn}$. The $\mathrm{Zn}$ concentration of the control with $\mathrm{Zn}$ was 5 times higher than that of plants without $\mathrm{Zn}$.

Based on our results, only strains CkDB5 and RrtHH10 were Zn-resistant. While CkDB5 and RrtHH10 presented identical MIC values (Table 2), the former indicated higher $\mathrm{ME}_{50}$ values than the latter (Table 2). With or without $\mathrm{Zn}, \mathrm{CkDB} 5$ could promote the growth response of tomato (Table 3). Ban et al. (2012) indicated that DSEFs are typical root endophytes, and they believed that potential effects of DSEFs on host plants should be considered. DSEFs can affect the heavy-metal uptake of their host plants and enhance the tolerance of these plants to heavy metal stress. DSEFs have also been shown to promote the growth response of their host plants (Gadd, 2007; Lin, 2016; Selosse et al., 2004). These fungi have been observed to transport absorbed nutrients to host plants to support their growth in harsh habitats (Deram et al., 2008; Likar and Regvar, 2009; Zhang et al., 2013).

\section{Conclusion}

Molecular analysis revealed that the six DSEFs studied in this work could be divided into five clusters; strain CoLG3 and CkDB2 were classified as W. laurinus, while strain RrtHH10 was classified as P. fortinii. Strain MoAL5 was classified as C. chaetospira, while strain RhYM6 was classified as Herpotrichiellaceae or Eurotiomycetes. Finally, strain CkDB5 was classified as $S$. humicola. These strains may be new species in the world or new species in the fungal flora of Taiwan. Of these six DSEFs, only strains CkDB5 and RrtHH10 were Zn-resistant and could promote the growth response of $S$. lycopersicum. Of the two endophytes, strain CkDB5 was more tolerant to $\mathrm{Zn}$ and showed better growth responses. CkDB5 is not only Zn-resistant, but it is also a promoter of tomato growth. 
Acknowledgements. The author appreciates the assistance of all members of Tree Mycorrhiza Laboratory in National Chiayi University.

\section{REFERENCES}

[1] Allen, S. E. (1989): Chemical Analysis of Ecological Materials. 2nd Ed. - Blackwell Scientific Publications, Oxford.

[2] Azcón-Aguilar, C., Barea, J. M. (1997): Applying mycorrhiza biotechnology to horticulture: significance and potentials. - Scientia Horticulturae 68(1): 1-24.

[3] Ban, Y., Tang, M., Chen, H., Xu, Z., Zhang, H., Yang, Y. (2012): The response of dark septate endophytes (DSE) to heavy metals in pure culture. - PloS One 7: e47968.

[4] Bradley, R., Burt, A. J., Read, D. J. (1981): Mycorrhizal infection and resistance to heavy metal toxicity in Calluna vulgaris. - Nature 292: 335-337.

[5] Dalpé, Y. (1986): Axenic synthesis of ericoid mycorrhiza in Vaccinium angustifoliurn Ait. by Oidiodendron species. - New Phytologist 103: 391-396.

[6] Deram, A., Languereau-Leman, F., Howsam, M., Petit, D., Van Haluwyn, C. (2008): Seasonal patterns of cadmium accumulation in Arrhenatherum elatius (Poaceae): influence of mycorrhizal and endophytic fungal colonisation. - Soil Biology and Biochemistry 40: 845-848.

[7] Diagne, N., Ngom, M., Djighaly, P. I., Ngom, D., Ndour, B., Cissokho, M., Faye, M. N., Sarr, A., Sy, M. O., Laplaze, L., Champion, A. (2015): Remediation of Heavy MetalContaminated Soils and Enhancement of Their Fertility with Actinorhizal Plants. - In Sherameti, I., Varma, A. (eds.) Heavy Metal Contamination of Soils. Springer, Switzerland, pp. 355-366.

[8] Diao, Y. H., Li, T., Zhao, Z. W. (2013): Zinc accumulation characteristics of two Exophiala strains and their antioxidant response to $\mathrm{Zn}^{2+}$ stress. - Journal of Environmental Protection 4: 12-19.

[9] Fernando, A. A., Currah, R. S. (1996): A comparative study of the effects of the root endophytes Leptodontidium orchidicola and Phialocephala fortinii (Fungi imperfecti) on the growth of some subalpine plants in culture. - Canadian Journal of Botany 74: 10711078.

[10] Gadd, G. M. (2007): Geomycology: biogeochemical transformations of rocks, minerals, metals and radionuclides by fungi, bioweathering and bioremediation. - Mycological Research 111: 3-49.

[11] Gardes, M., Bruns, T. D. (1993): ITS primers with enhanced specificity for basidomycetes - applications to the identification of mycorrhizae and rusts. - Molecular Ecology 1: 113-118.

[12] Gibson, B. R., Mitchell, D. T. (2005): Influence of pH on copper and zinc sensitivity of ericoid mycobionts in vitro. - Mycorrhiza 15: 231-234.

[13] Helmisaari, H. S., Salemaa, M., Derome, J., Kiikkilä, O., Uhlig, C., Nieminen, T. M. (2007): Remediation of heavy metal contaminated forest soil using recycled organic matter and native woody plants. - Journal of Environmental Quality 36: 1145-1153.

[14] Hong, S. L., Lin, T. C., Lin, L. C. (2014): Preliminary study on morphology of rootfungus association of Cinnamomum kanehirai at Dabang area. - Quarterly Journal of Chinese Forestry 47: 393-398 (in Chinese).

[15] Hutton, B. J., Dixon, K. W., Sivasithamparam, K. (1994): Ericoid endophytes of western Australian heaths (Epacridaceae). - New Phytologist 127: 557-566.

[16] Jaeckel, P., Krauss, G. J., Krauss, G. (2005): Cadmium and zinc response of the fungi Heliscus lugdunensis and Verticillium cf. alboatrum isolated from highly polluted water. - Science of the Total Environment 346: 274-279. 
[17] Jumpponen, A., Mattson, K. G., Trappe, J. M. (1998): Mycorrhizal functioning of Phialocephala fortinii with Pinus contorta on glacier forefront soil: interactions with soil nitrogen and organic matter. - Mycorrhiza 7: 261-265.

[18] Li, H. Y., Li, D. W., He, C. M., Zhou, Z. P., Mei, T., Xu, H. M. (2012): Diversity and heavy metal tolerance of endophytic fungi from six dominant plant species in a $\mathrm{Pb}-\mathrm{Zn}$ mine wasteland in China. - Fungal Ecology 5: 309-315.

[19] Likar, M., Regvar, M. (2009): Application of temporal temperature gradient gel electrophoresis for characterisation of fungal endophyte communities of Salix caprea L. in a heavy metal polluted soil. - Science of the Total Environment 407: 6179-6187.

[20] Lin, L. C. (2016): Growth effect of Cinnamomum kanehirae cuttings associated with its dark septate endophytes. - Pakistan Journal of Biological Sciences 19: 299-305.

[21] Lin, L. C., Lee, M. J., Chen, J. L. (2011): Decomposition of organic matter by the ericoid mycorrhizal endophytes of Formosan rhododendron (Rhododendron formosanum Hemsl.). - Mycorrhiza 21: 331-339.

[22] Marx, D. H. (1969): The influence of ectotrophic mycorrhizal fungi on the resistance of pine roots to pathogenic infections. I. Antagonism of mycorrhizal fungi to root pathogenic fungi and soil bacteria. - Phytopathology 59: 153-163.

[23] Mathew, A., Malathy, R. M. (2008): The evidence of mycorrhizal fungi and dark septate endophytes in roots of Chlorophytum borivillianum. - Acta Botanica Croatica 67(1): 9196.

[24] Monnet, F., Vaillant, N., Hitmi, A., Coudret, A., Sallanon, H. (2001): Endophytic Neotyphodium lolii induced tolerance to $\mathrm{Zn}$ stress in Lolium perenne. - Physiologia Plantarum 113: 557-563.

[25] Newsham, K. K. (1999): Phialophora graminicola, a dark septate fungus, is a beneficial associate of the grass Vulpia ciliata ssp. ambigua. - New Phytologist 144: 517-524.

[26] Phosri, C., Martin, M. P., Sihanonth, P., Whalley, A. J. S., Watling, R. (2007): Molecular study of the genus Astraeus. - Mycological Research 3: 275-286.

[27] Piercey, M. M., Thormann, M. N., Currah, R. S. (2002): Saprobic characteristics of three fungal taxa from ericalean roots and their association with the roots of Rhododendron groenlandicum and Picea mariana in culture. - Mycorrhiza 12: 175-180.

[28] Piercey, M. M., Graham, S. W., Currah, R. S. (2004): Patterns of genetic variation in Phialocephala fortinii across a broad latitudinal transect in Canada. - Mycological Research 108(8): 955-964.

[29] Ramos, R. L. L., Jacome, A. B., Barron, J. M., Rubio, L. F., Coronado, R. G. (2002): Adsorption of zinc (II) from an aqueous solution onto activated carbon. - Journal of Hazardous Materials 90: 27-38.

[30] Saitou, N., Nei, M. (1987): The neighbor-joining method: a new method for reconstructing phylogenetic trees. - Molecular Biology and Evolution 4: 406-425.

[31] Schmid, E., Obnerwikler, F., Gomez, L. D. (1995): Light and electron microscopy of a host-fungus interaction in the roots of some epiphytic ferns from Costa Rica. - Canadian Journal of Botany 73: 991-996.

[32] Selosse, M. A., Baudoin, E., Vandenkoornhuyse, P. (2004): Symbiotic microorganisms, a key for ecological success and protection of plants. - Comptes Rendus Biologies 327: 639-648.

[33] Shivanna, M. B., Meera, M. S., Hyakumachi, M. (1994): Sterile fungi from zoysiagrass rhizosphere as plant-growth promoters in spring wheat. - Canadian Journal of Microbiology 40(8): 637-644.

[34] Sigler, L., Flis, A. L. (1998): Catalogue of the University of Alberta Microfungus Collection and Herbarium. 3 nd Ed. - University of Alberta, Edmonton.

[35] Smith, S. E., Read, D. J. (1997): Mycorrhizal Symbiosis. 2nd Ed. - Academic Press, London.

[36] Sun, X., Guo, L. D., Hyde, K. D. (2011): Community composition of endophytic fungi in Acer truncatum and their role in decomposition. - Fungal Diversity 47: 85-95. 
[37] Tamura, K., Peterson, D., Peterson, N., Stecher, G., Nei, M., Kumar, S. (2011): MEGA5: Molecular evolutionary genetics analysis using maximum likelihood, evolutionary distance, and maximum parsimony methods. - Molecular Biology and Evolution 28(10): 2731-273.

[38] Tan, Y. L., Chang, T. P., Chen, J. L., Ku, K. L., Lin, L. C. (2016): Morphology of rootfungus association of Mahonia oiwakensis and its endophytes. - Quarterly Journal of Chinese Forestry 49: 1-12 (in Chinese).

[39] Upadhyaya, H., Panda, S. K., Bhattacharjee, M. K., Dutta, S. (2010): Role of arbuscular mycorrhiza in heavy metal tolerance in plants: prospects for phytoremediation. - Journal of Phytology 2: 16-27.

[40] Wainwright, M., Gadd, G. M. (1997): Fungi and Industrial Pollutants. - In: Wicklow, D. T., Söderström, B. (eds.) The Mycota IV. Environmental and Microbial Relationships. Springer, Berlin.

[41] Xu, R., Li, T., Cui, H., Wang, J., Yu, X., Ding, Y., Wang, C., Yang, Z., Zhao, Z. (2015): Diversity and characterization of Cd-tolerant dark septate endophytes (DSEs) associated with the roots of Nepal alder (Alnus nepalensis) in a metal mine tailing of southwest China. - Applied Soil Ecology 93: 11-18.

[42] Yang, Y., Liang, Y., Ghosh, A., Song, Y., Chen, H., Tang, M. (2015): Assessment of arbuscular mycorrhizal fungi status and heavy metal accumulation characteristics of tree species in a lead-zinc mine area: potential applications for phytoremediation. Environmental Science and Pollution Research 22: 13179-13193.

[43] Zeng, M., Liao, B. H., Lei, M., Zhang, Y., Zeng, Q., Ouyang, B. (2008): Arsenic removal from contaminated soil using phosphoric acid and phosphate. - Journal of Environmental Sciences 20: 75-79.

[44] Zhang, X., Li, C., Nan, Z. (2010): Effects of cadmium stress on growth and anti-oxidative systems in Achnatherum inebrians symbiotic with Neotyphodium gansuense. - Journal of Hazardous Materials 175: 703-709.

[45] Zhang, Y., Zhang, Y., Liu, M., Shi, X., Zhao, Z. (2008): Dark septate endophyte (DSE) fungi isolated from metal polluted soils: Their taxonomic position, tolerance, and accumulation of heavy metals in vitro. - Journal of Microbiology 46: 624-632.

[46] Zhang, Y., Li, T., Zhao, Z. (2013): Colonization characteristics and composition of dark septate endophytes (DSE) in a lead and zinc slag heap in southwest China. - Soil and Sediment Contamination: An International Journal 22: 532-545. 